University of Nebraska - Lincoln

DigitalCommons@University of Nebraska - Lincoln

Publications, Agencies and Staff of the U.S.

Department of Commerce

U.S. Department of Commerce

2004

Relating Size of Juveniles to Survival Within And Among

Populations of Chinook Salmon

\author{
Richard Zabel \\ National Marine Fisheries Service, rich.zabel@noaa.gov \\ Stephen Achord \\ National Marine Fisheries Service
}

Follow this and additional works at: https://digitalcommons.unl.edu/usdeptcommercepub

Zabel, Richard and Achord, Stephen, "Relating Size of Juveniles to Survival Within And Among Populations of Chinook Salmon" (2004). Publications, Agencies and Staff of the U.S. Department of Commerce. 484. https://digitalcommons.unl.edu/usdeptcommercepub/484

This Article is brought to you for free and open access by the U.S. Department of Commerce at DigitalCommons@University of Nebraska - Lincoln. It has been accepted for inclusion in Publications, Agencies and Staff of the U.S. Department of Commerce by an authorized administrator of DigitalCommons@University of Nebraska - Lincoln. 


\title{
RELATING SIZE OF JUVENILES TO SURVIVAL WITHIN AND AMONG POPULATIONS OF CHINOOK SALMON
}

\author{
Richard W. ZABEL ${ }^{1}$ AND STEPHEN ACHORD \\ National Marine Fisheries Service, 2725 Montlake Boulevard E., Seattle, Washington 98112 USA
}

\begin{abstract}
Understanding relationships between the size of individuals and their subsequent survival can not only provide insights into mechanisms of mortality, but can also identify traits to measure for monitoring at-risk populations. We analyzed a data set of more than 54000 juvenile chinook salmon (Oncorhynchus tshawytscha) from 15 populations over five years. The juveniles were tagged during the summer in their freshwater rearing habitats and then recaptured at downstream sites the following spring after an extended rearing and overwintering period. We measured the length and weight of fish at tagging and computed a "condition index" that determined how fat or thin a fish was relative to others. Among populations, mean length and mean condition index were poor predictors of survival, but we did detect year and site effects. Within populations, survival was strongly related to the relative length of individuals but not to relative condition index. Our results are consistent with length-related mechanisms of mortality mediated by hierarchical behavior, and thus merely measuring changes in mean values of morphological traits in populations of juveniles may provide little insight into expected changes in population viability. Expanding upon these results, we predicted a nearly $60 \%$ increase in selection for juvenile fish length when we extended our observation period through adulthood. Thus, monitoring populations through only a portion of their life history may present an incomplete picture of their survival variability.
\end{abstract}

Key words: chinook salmon; endangered species; fish condition; fish length; fish mass; life-stage survival; mortality mechanisms in natural populations; Oncorhynchus tshawytscha; recovery planning; selective mortality.

\section{INTRODUCTION}

Many ecological processes are mediated by the size or condition of individuals involved (Łomnicki 1988). In some instances, absolute size is the overriding factor: for example, the size of a prey may determine whether it is consumable by a predator (Stephens and Krebs 1986). In other cases, relative size is more important: the outcome of competitive interactions, for example, is often determined by the rank in some trait of the individuals involved (Sutherland 1996). By pinpointing precise aspects of individual phenotypes that are associated with survival and by determining how these relationships vary within and among closely related populations, we can differentiate between absolute and relative size effects and potentially develop insights into mechanisms of mortality.

This type of information is particularly valuable for at-risk populations because most population viability analyses ignore variability among individuals. These analyses commonly recommend how improvements in a particular age- or stage-specific survival rate will lead to increased population growth rate and hence enhanced population viability (Lande 1988, Crowder et al. 1994, Doak et al. 1994, Kareiva et al. 2000, Wisdom et al. 2000). However, to actually achieve these im-

Manuscript received 15 November 2002; revised 18 July 2003; accepted 21 July 2003. Corresponding Editor: J. R. Bence.

${ }^{1}$ E-mail: Rich.Zabel@noaa.gov provements, we need to gain an understanding of stagespecific mortality processes and how they might respond to mitigation efforts. Further, if we can identify traits that correlate with survival, then these traits might become a valuable foundation for population monitoring programs. Indeed, the majority of U.S. Endangered Species Act recovery plans include monitoring demographic aspects of target populations (Campbell et al. 2002).

The condition of individuals is determined by a combination of factors (Begon et al. 1996): nutrient production and availability, inter- and intraspecific competition for resources, abundance of predators (which may affect foraging behavior; Werner and Anholt 1993, Werner and Gilliam 1984), and physical habitat quality, among others. Forces that affect these factors, such as habitat degradation or nonindigenous species, have been identified as threats to many at-risk populations (Lawler et al. 2002), and thus many recovery plans focus on mitigating these forces. While it is of great importance to understand how these factors contribute to the condition of individuals, we focused on an equally important question: how does the variability in the condition of individuals, both within and among populations, relate to survival?

This question is particularly difficult to address in species with complex life histories (Wilbur 1980, Werner 1988) such as those that undergo metamorphoses 
or extensive migrations. One complication is that the condition an individual attains in one life stage may not confer survival advantages until a later life stage. For example, the condition of juvenile toads (Goater 1994), larval reef fish (Searcy and Sponaugle 2001), or larval mussels (Phillips 2002) influences their postmetamorphic survival. Also, monitoring populations as they undergo metamorphosis or during a migration presents logistical challenges. Although estimating survival for species with complex life histories is challenging, recent advances in statistical theory (e.g., Burnham et al. 1987, Lebreton et al. 1992), software (e.g., MARK, [White and Burnham 1999]), and animal tagging technology (e.g., passive integrated transponder [PIT] tags, [Prentice et al. 1990]) have enabled much more detailed analyses of survival processes than were previously possible.

Here, we report on analyses based on a long-term monitoring effort on Snake River spring/summer chinook salmon (Oncorhynchus tshawytscha), listed as a threatened Evolutionarily Significant Unit (ESU) under the U.S. Endangered Species Act. We tagged and measured more than 54000 juveniles over five years in 15 separate streams. The fish were recaptured the following spring after transformation to a migratory life stage and after undergoing an extensive migration, and survival was estimated from release to recapture. Mortality is considerable during this freshwater rearing phase of wild chinook salmon populations, but mechanisms of this mortality are poorly understood (Healy 1991). Kareiva et al. (2000) predicted that modest improvements in survival during this life stage would substantially improve the probability of recovering this ESU. By relating individual and population-level traits to juvenile survival, we provide an overview of factors that explain variation in survival both among and within salmon populations. The results from this type of analysis can provide insights into potential gains in population viability in response to mitigation efforts.

One caveat to this approach is that the condition of individuals during one life stage may affect survival beyond the period measured, and thus it is imperative to consider the interdependency of life stages. After we present our main results, we consider how the condition of individuals as juveniles might affect their performance in subsequent life stages.

\section{Methods}

\section{Snake River spring/summer chinook salmon}

Snake River spring/summer chinook spawn in small tributaries in Idaho and Oregon of the northwestern United States, where juveniles spend their initial rearing period (Matthews and Waples 1991). Fish in this Evolutionarily Significant Unit (ESU) are considered "stream-type" chinook (Gilbert 1912), meaning they spend a full year in freshwater before initiating seaward migration. Most stream-type juveniles emigrate from their natal streams in late summer and fall to overwinter in larger rivers (Healy 1991) and initiate seaward migration the following spring after undergoing smoltification, a series of physiological, morphological, and behavioral changes to prepare the fish for seawater residence (Hoar 1976, Folmar and Dickhoff 1980). Snake River spring/summer chinook spend $1-3 \mathrm{yr}$ in the $\mathrm{Pa}-$ cific Ocean where they undergo the majority of growth before returning to spawn as adults.

We tagged fish in high-elevation streams (mostly above $1500 \mathrm{~m}$ ) in the Salmon River sub-basin in Idaho (Fig. 1). These streams represent a broad spectrum in terms of habitat quality (Paulsen and Fisher 2001), physical features such as temperature regimes, and presence or absence of nonindigenous predators (Achord et al. 1996, 2001) which may compete with or prey upon juvenile chinook (Levin et al. 2002, Achord et al. 2003). For convenience, we refer to the fish from each tagging site as a population. The migration distance from natal streams in Idaho to the Pacific Ocean is extensive, ranging from 1124 to 1440 $\mathrm{km}$, and the migrants must pass eight hydroelectric dams in the lower Snake and Columbia Rivers.

\section{Data}

We analyzed data from juveniles that we collected by seining and electroshocking in their rearing areas during summer of the years 1992, 1993, 1994, 1998, and 1999. We excluded other years from the analysis because six or fewer streams were sampled in those years. We also limited our analysis to fish we tagged in the Salmon River Basin to ensure standardized methodology and to limit geographically based genetic variation (Mathews and Waples 1991). Details of the collection and tagging procedures are provided by Achord et al. $(1996,2001)$. Captured fish were brought to a mobile field station, anesthetized, the fork length of each fish was recorded, and a subset of fish was weighed, weather permitting. A PIT tag was inserted into the body cavity of each fish. PIT tags are glass encapsulated transponder coils, $\sim 12 \mathrm{~mm}$ in length, that are uniquely coded and retained by the individual for life (Prentice et al. 1990). Fish below 50-55 $\mathrm{mm}$ in length were not tagged, but for most populations, this represented a small proportion of the sample (Achord et al. 2001). Several studies have demonstrated no adverse or size-related effects of PIT tags on fish in the size ranges we tagged (salmon [Prentice et al. 1990, Peterson et al. 1994], Eurasian perch [Baras et al. 2000]). The results of Peterson et al. (1994) are particularly relevant to this study since they monitored survival through an overwintering period.

PIT-tagged fish were automatically detected in juvenile bypass systems at hydroelectric dams on the mainstem Snake and Columbia Rivers during their seaward migration in the spring following tagging. Thus we monitored fish that progressed through several life stages: summer rearing, overwintering, transformation 


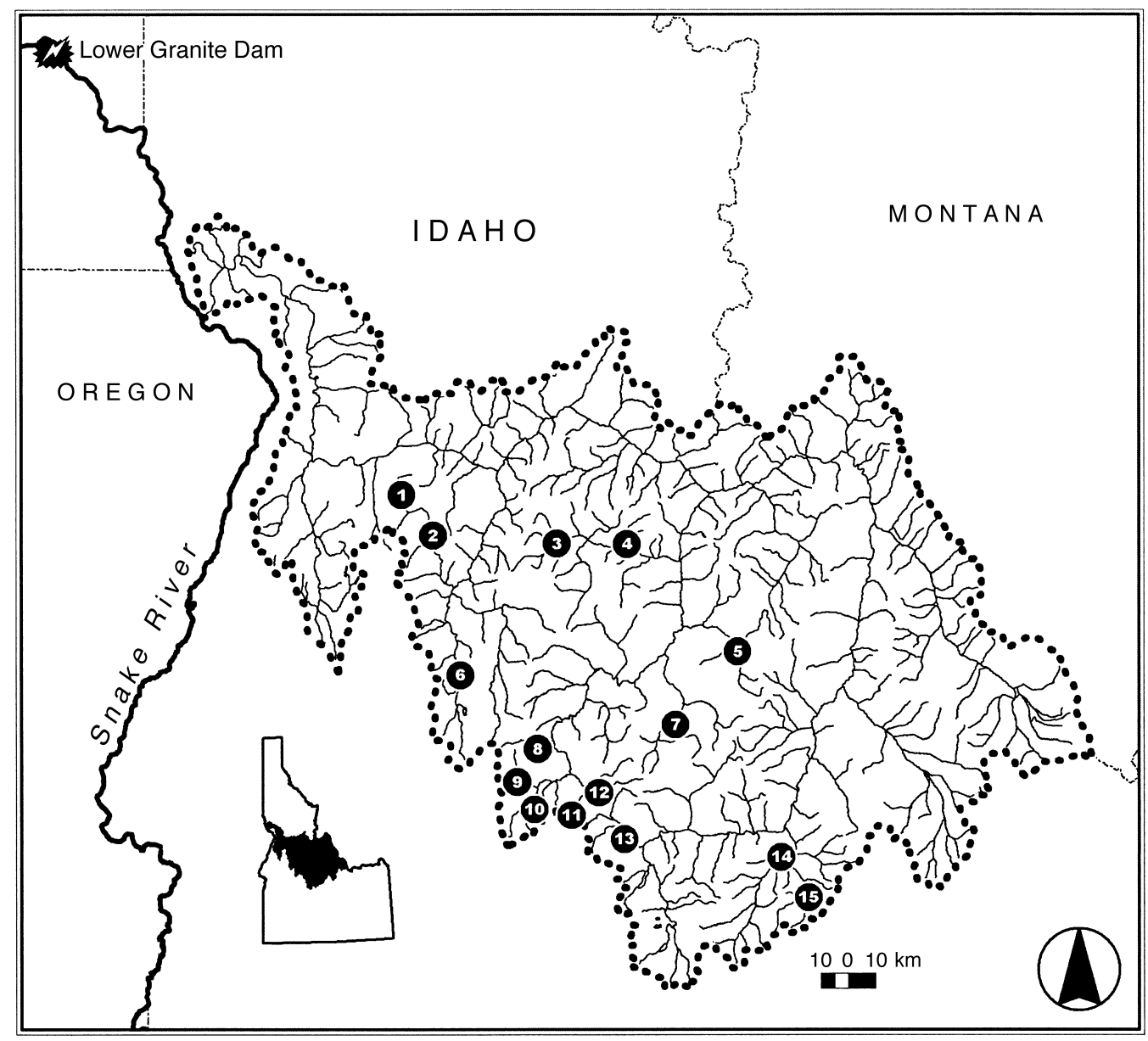

FIG. 1. Salmon River Basin and Lower Granite Dam in the northwest United States. The numbered points identify the locations of the tagged populations of chinook salmon. Key: 1, Lake Creek; 2, Secesh River; 3, upper Big Creek; 4, lower Big Creek; 5, Camas Creek; 6, south fork Salmon River; 7, Loon Creek; 8, Sulphur Creek; 9, Elk Creek; 10, Bear Valley Creek; 11, Cape Horn Creek; 12, Marsh Creek; 13, Valley Creek; 14, east fork Salmon River; 15, Herd Creek.

to a migratory stage, and finally the initiation of seaward migration. Although we did not physically recapture the individuals, we use the term "recapture" for consistency with previous studies. Each fish had a capture history, which took on a value of 1 (observed), 0 (not observed), or -1 (removed) at each recapture site. We defined two recapture sites: Lower Granite Dam and any site downstream from Lower Granite Dam. Thus capture histories (ignoring removed fish) were of the following combinations: 11 (observed at Lower Granite Dam and below); 10 (observed at Lower Granite Dam but not below); 01 (not observed at Lower Granite Dam but below); or 00 (not observed at Lower Granite Dam or below). The total number of fish with each capture history is designated as $X_{11}, X_{10}, X_{01}$, and $X_{00}$. These capture-history data were used to estimate survival from release to Lower Granite Dam using methods described in detail in Methods: Survival estimation and modeling.

In addition to recapture data, we also identified covariates that were potentially related to survival. The covariates were either group covariates (site and year) or continuous covariates based on measurements of individuals. All continuous covariates were standardized to have zero mean and unit variance. We separated the length covariate $\left(l_{i, s, y}\right)$ into a mean length for each site by year $\left(\bar{L}_{s, y}\right)$ and a deviation of each individual from its yearly population mean $\left(\delta_{i, s, y}\right)$. This allowed us to examine length effects among populations and a relative size effect within populations. Mass was highly correlated with length, so we did not examine its effects directly. However, we incorporated mass into a modification of the Fulton condition index (Ricker 1975, Anderson and Gutreuter 1983) to determine how fat or thin a fish was for a given length compared to the overall population. We did this by first performing a nonlinear regression of $W_{i}=a L_{i}^{b}+\varepsilon_{i}$ for all fish combined, where $W_{i}$ is the mass $(\mathrm{g})$ of the $i$ th individual, $L_{i}$ is its length $(\mathrm{mm})$, and $\varepsilon$ is a normally distributed error term (Fig. 2). The "condition index," $K_{i}$, was then calculated as the deviation in mass (vertical direction) of an individual from the regression curve. As 


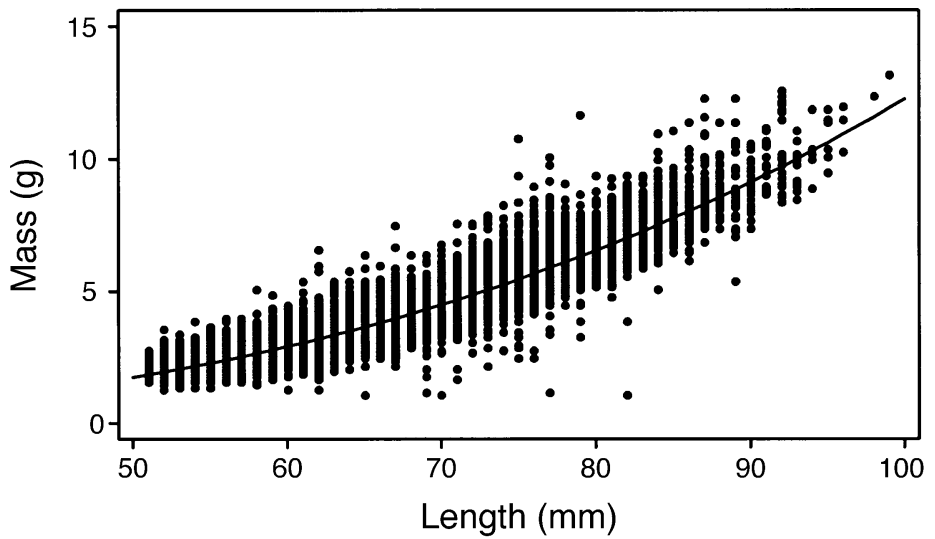

FIG. 2. Relationship between mass (g) and length $(\mathrm{mm})$ at tagging. The line was derived from the nonlinear regression $W_{i}=a L_{i}^{b}, R^{2}=$ $0.857 ; a=2.87 \times 10^{-5}\left(1 \mathrm{SE}=8.31 \times 10^{-7}\right)$; $b=2.81(1 \mathrm{SE}=0.0068) ; P<0.001$. with the length covariate, we separated each $K_{i, s, y}$ into a mean $K$ for the population $\left(\bar{K}_{s, y}\right)$ and a deviation of each individual from its yearly population mean $\left(\delta_{i, s, y}\right)$. Since mass was only measured for a subset of fish, the examination of the condition index covariate was performed on a subset of the data. If fewer than 50 fish were weighed in a stream in a year, condition index was eliminated from the analysis for the stream-year combination.

\section{Survival estimation and modeling}

The main focus of our analysis was to determine which factors, at the individual and population level, were related to survival from point of release in Idaho tributaries to Lower Granite Dam, the first dam encountered on the lower Snake River (Fig. 1). To do this required developing a model describing all aspects of the data, including both survival and probability of recapture. In developing the model, we adopted the terminology and notation of Lebreton et al. (1992, 1993), although we did simplify the notation for our particular application.

The first step in the model development was to assign probabilities to each of the possible recapture histories for released fish: $P_{10}, P_{11}, P_{01}$, and $P_{00}$. Next these prob- abilities were incorporated into a multinomial model with the following likelihood function:

$$
L=C\left(P_{10}\right)^{x_{10}}\left(P_{11}\right)^{x_{11}}\left(P_{01}\right)^{x_{01}}\left(P_{00}\right)^{x_{00}}
$$

where $C$ is a combinatorial coefficient. These probabilities are related to three quantities that can vary by individual or release group: (1) $\phi$, the probability of survival from release to Lower Granite Dam; (2) $p$, the probability of recapture at Lower Granite Dam given an individual survived to that point; and (3) $\beta$, which combines the probability of surviving from the upstream recapture site to the downstream recapture site and the probability of recapture at the downstream site since the data cannot distinguish between these two probabilities (Fig. 3).

We related the survival and recapture probabilities to the probabilities of observing the data as follows:

$$
\begin{aligned}
& P_{11}=\phi p \beta \quad P_{10}=\phi p(1-\beta) \\
& P_{01}=\phi(1-p) \beta \\
& P_{00}=(1-\phi)+\phi(1-p)(1-\beta) .
\end{aligned}
$$

$P_{11}$, for example, is the probability of a fish surviving to the first recapture site $(\phi)$ multiplied by the probability of recapture there $(p)$ multiplied by the proba-

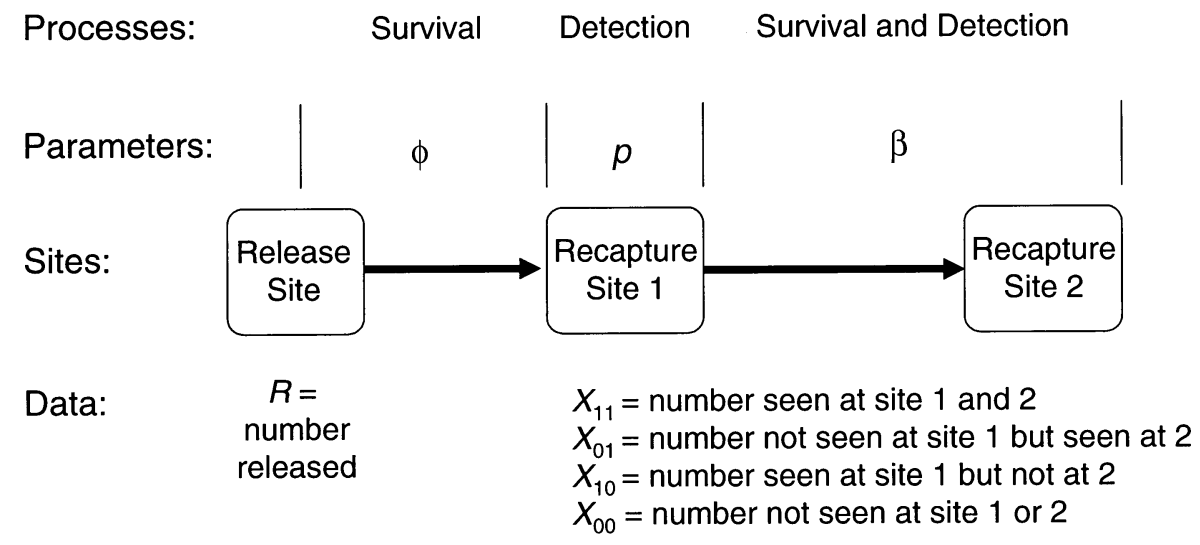

FIG. 3. Schematic diagram of the capture history data, the processes that produced them, and the model parameters. 
TABle 1. Description of the group covariate submodels for $\phi$ (survival), $p$ (recapture probability), and $\beta$ (combined downstream survival and recapture probability).

\begin{tabular}{lcl}
\hline \hline \multicolumn{1}{c}{ Submodel } & Params & \multicolumn{1}{c}{ Description } \\
\hline$\phi$ or $p$ or $\beta$ & 1 & parameter constant across sites and years \\
$\phi(y)$ or $p(y)$ or $\beta(y)$ & 5 & parameter varies by year but constant across sites \\
$\phi(s)$ or $p(s)$ or $\beta(s)$ & 15 & parameter varies by site but constant across years \\
$\phi(s+y)$ or $p(s+y)$ or $\beta(s+y)$ & 19 & parameter determined by a site and year term \\
$\phi(s y)$ or $p(s y)$ or $\beta(s y)$ & 71 & unique parameter for each site/year combination \\
\hline
\end{tabular}

Notes: Params is the number of parameters for each submodel. A full model is obtained by choosing one submodel for each of $\phi, p$, and $\beta$. The total number of parameters is obtained by adding up the number of parameters associated with each submodel.

bility of surviving through the downstream reach and recapture at a downstream site $(\beta)$. The terms in Eq. 2 were substituted into Eq. 1 to a create a likelihood function in terms of survival and recapture probabilities. This likelihood function was then slightly modified to accommodate the small number of fish that were removed at Lower Granite Dam. This likelihood function was used to estimate model parameters and compare the performance of competing models, as described in the following paragraphs.

If a unique $\phi, p$, and $\beta$ is specified for each of the 71 site-year combinations, this "saturated" model contains 273 parameters. We modified the saturated model in two ways: (1) $\phi, p$, and $\beta$ were held constant across years or sites to produce submodels with reduced numbers of parameters (Table 1); and (2) survival and recapture probabilities were related to the continuous covariates.

We used the logit link function to incorporate predictor variables into the model. This ensured that the model parameters were constrained between 0 and 1 , which is appropriate since they are probabilities. For example, the response of survival to a site (population) effect, a year effect, and a continuous covariate $x$ is

$\phi\left(s+y+x_{i}\right)=\frac{\exp \left(\alpha_{0}+\alpha_{s}+\alpha_{y}+\alpha_{1} x_{i}\right)}{1+\exp \left(\alpha_{0}+\alpha_{s}+\alpha_{y}+\alpha_{1} x_{i}\right)}$

where the $\alpha$ 's are fitted coefficients. The group parameters $\alpha_{s}$ and $\alpha_{y}$ are associated with "dummy variables" (group covariates) that designate groups of fish defined by site or year. We also used the logit link for $p$ and $\beta$ parameters. Parameters were estimated by numerically maximizing the log-likelihood function with respect to the parameters using the software program MARK (White and Burnham 1999).

To examine the contribution of the covariates to model fit, we compared alternative models comprising various combinations of variables using Akaike's Information Criterion (AIC; Akaike 1973, Burnham and Anderson 1998). AIC rewards better model fits (as measured by the log-likelihood, $L$ ) while penalizing for extra parameters:

$$
\mathrm{AIC}=-2 L+2 N
$$

where $N$ is the number of parameters. Smaller AIC values indicate "better" models. When comparing two models we computed the difference in AIC values, or $\triangle$ AIC. According to Burnham and Anderson (1998), a $\triangle \mathrm{AIC}$ of less than 2 indicates little difference between competing models; a $\Delta \mathrm{AIC}$ of $2-10$ indicates moderate support for a difference between the models, and a $\triangle \mathrm{AIC}$ of greater than 10 indicates strong support. We chose AIC over alternative methods such as a Likelihood Ratio Test (Mood et al. 1974) because it applies to nested and non-nested models.

Since survival and recapture probabilities are intimately related in the data, it is imperative to specify recapture probabilities as accurately as possible (MacKenzie and Kendall 2002). Thus we adopted the strategy of Lebreton et al. (1992) by analyzing the recapture probabilities before modeling survival to the first recapture site $(\phi)$. A feature of this strategy is that once the structure of the "nuisance" parameters is set, these parameters cancel out when comparing alternative survival models. We began with the saturated model for both survival and recapture probabilities; this model is designated as $\phi(s y) p(s y) \beta(s y)$. Then, using the model selection criteria described above, we determined whether first $\beta$ and then $p$ could be reduced to simpler combinations of site and year effects (Table 1 ). Once we selected models for $p$, we tested whether recapture probabilities were related to overall fish length (l) because if so, this would confound the survival analysis. We only examined overall length here because we expected any length effects at the downstream recapture site to apply to all fish equally since the populations are mixed at this point.

Once the structure of the $p$ and $\beta$ parameters was set, we developed alternative models of survival to the first recapture site $(\phi)$ in relation to fish length. We always began with a model containing various combinations of group covariates (including models with no group covariates) and then examined the effect of adding the length covariates. We defined a "group" of models as those that had the same group covariates but various combinations of length covariates, and we compared AIC values within groups. To limit the number of models, if a length covariate did not improve model fit $($ AIC $<2.0)$ when added to a group covariate, it was not included in more complex models containing that group covariate. We also compared all models incor- 
TABLE 2. Number of fish tagged (abbreviated $N$ ), survival estimates (abbreviated Surv) with standard errors (abbreviated $\mathrm{SE}$ ) in parentheses, and mean lengths (in $\mathrm{mm}$ ) with standard errors in parentheses for each population by year of tagging.

\begin{tabular}{|c|c|c|c|c|c|c|}
\hline \multirow[b]{2}{*}{ Population } & \multicolumn{3}{|c|}{1992} & \multicolumn{3}{|c|}{1993} \\
\hline & $N$ & Surv (SE) & Length (SE) & $N$ & Surv (SE) & Length (SE) \\
\hline Bear Valley Creek & 1014 & $0.160(0.026)$ & $73.54(0.17)$ & 856 & $0.215(0.020)$ & $63.11(0.19)$ \\
\hline Big Creek, Lower & 282 & $0.325(0.044)$ & $79.50(0.32)$ & 186 & $0.294(0.036)$ & $69.55(0.43)$ \\
\hline Big Creek, Upper & 451 & $0.086(0.013)$ & $71.20(0.26)$ & 535 & $0.120(0.028)$ & $64.13(0.24)$ \\
\hline Camas Creek & 1012 & $0.209(0.033)$ & $68.41(0.20)$ & 215 & $0.233(0.046)$ & $63.57(0.42)$ \\
\hline Cape Horn Creek & 205 & $0.148(0.029)$ & $67.00(0.35)$ & & & \\
\hline Elk Creek & 628 & $0.116(0.017)$ & $77.36(0.19)$ & 998 & $0.158(0.016)$ & $64.09(0.19)$ \\
\hline Herd Creek & 224 & $0.150(0.035)$ & $78.26(0.35)$ & 119 & $0.168(0.037)$ & $74.01(0.49)$ \\
\hline Lake Creek & 255 & $0.228(0.039)$ & $72.01(0.35)$ & 252 & $0.105(0.021)$ & $61.95(0.41)$ \\
\hline Loon Creek & 261 & $0.347(0.136)$ & $69.99(0.31)$ & 396 & $0.259(0.038)$ & $63.58(0.29)$ \\
\hline Marsh Creek & 1000 & $0.133(0.014)$ & $70.57(0.17)$ & 944 & $0.183(0.019)$ & $67.99(0.22)$ \\
\hline E. Fork Salmon River & 843 & $0.078(0.012)$ & $75.50(0.21)$ & 883 & $0.123(0.016)$ & $72.05(0.19)$ \\
\hline S. Fork Salmon River & 998 & $0.152(0.017)$ & $67.99(0.16)$ & 803 & $0.134(0.021)$ & $59.45(0.18)$ \\
\hline Secesh River & 327 & $0.180(0.032)$ & $68.48(0.30)$ & 422 & $0.126(0.018)$ & $60.56(0.30)$ \\
\hline Sulfur Creek & 712 & $0.088(0.020)$ & $70.77(0.19)$ & & & \\
\hline Valley Creek & 1026 & $0.080(0.012)$ & $73.03(0.20)$ & 848 & $0.132(0.017)$ & $67.04(0.24)$ \\
\hline
\end{tabular}

Note: Survival estimates and their standard errors were based on the "saturated" model where a unique survival was estimated for each site/year combination.

porating different submodels for $\phi$ to determine the overall "best" model.

We adopted a similar strategy when we analyzed (using the reduced data set) the effects of condition index $(K)$ on survival. To simplify the calculations, we assumed that $p$ and $\beta$ varied with respect to the group covariates in the same way that they did for the full data set. Since $K$ was the deviation of a fish's mass from the mass-length relationship, we controlled for length effects by incorporating the overall length covariate in some of the condition index models.

This modeling exercise required several assumptions, including: the fate of each individual is independent of the fates of all others; all fish in a group have equal survival and recapture probabilities; and prior recapture history has no effect on subsequent survival and recapture probabilities (Skalski et al. 1998). Burnham et al. (1987) proposed several tests to assess these assumptions, but they require three downstream recapture sites. Although we could not test these assumptions explicitly, Skalski et al. (1998) found the survival estimates robust to many violations of as-

TABLE 3. Results obtained from models based on varying the $\beta$ parameters (combined downstream survival and recapture probability) with respect to site $(s)$ and year $(y)$ while holding fixed the structure of the $\phi$ (survival) and $p$ parameters (recapture probability).

\begin{tabular}{lcc}
\hline \multicolumn{1}{c}{ Model } & No. parameters & AIC \\
\hline 3a) $\phi(s y) p(s y) \beta$ & 143 & 52777.74 \\
3b) $\phi(s y) p(s y) \beta(y)$ & $\mathbf{1 4 7}$ & $\mathbf{5 2 6 6 7 . 1 5}$ \\
$3 \mathrm{c}) \phi(s y) p(s y) \beta(s)$ & 157 & 52781.38 \\
$3 \mathrm{~d}) \phi(s y) p(s y) \beta(s+y)$ & 161 & 52681.54 \\
3e) $\phi(s y) p(s y) \beta(s y)$ & 213 & 52715.93 \\
\hline
\end{tabular}

Notes: See Table 1 for a description of the submodels. The best-fit model (lowest Akaike's Information Criteria [AIC] value) was one where $\beta$ varied on a yearly basis (indicated in bold). sumptions. Also, survival estimates, in general, are more robust to assumption violations than are estimates of abundance (Lebreton et al. 1992).

\section{RESULTS}

We tagged 54004 fish in 71 separate population/year combinations (Table 2). Based on the saturated model, population survival ranged from $7.8 \%$ to $38.5 \%$, and recapture probabilities at Lower Granite Dam ranged from 0.184 to 0.725 . Mean length by population ranged from $59.45 \mathrm{~mm}$ to $79.52 \mathrm{~mm}$ (Table 2).

We reduced the dimension of the model substantially by relating $\beta$ and $p$ to group factors. For $\beta$, we selected a model where $\beta$ varied yearly (Table 3 ), and in doing so reduced the number of $\beta$ parameters from 71 to 5 . For $p$, we selected a model where it varied according to the sum of a site and year term (Table 4), which had 19 parameters. When we added the length covariate to this model for $p$, model performance decreased. Thus,

TABLE 4. Results obtained from models based on varying the $p$ parameters (recapture probability) with respect to site $(s)$, year $(y)$, and length $(l)$ while holding fixed the structure of the $\phi$ (survival) and $\beta$ parameters (combined downstream survival and recapture probability).

\begin{tabular}{lcc}
\hline \hline \multicolumn{1}{c}{ Model } & $\begin{array}{c}\text { No. } \\
\text { parameters }\end{array}$ & AIC \\
\hline 4a) $\phi(s y) p \beta(y)$ & 77 & 52871.53 \\
4b) $\phi(s y) p(y) \beta(y)$ & 81 & 52648.66 \\
$4 \mathrm{c}) \phi(s y) p(s) \beta(y)$ & 91 & 52848.25 \\
4d) $\phi(s \boldsymbol{y}) \boldsymbol{p}(\boldsymbol{s}+\boldsymbol{y}) \boldsymbol{\beta}(\boldsymbol{y})$ & $\mathbf{9 5}$ & $\mathbf{5 2 6 4 0 . 4 0}$ \\
4e) $\phi(s y) p(s+y+l) \beta(y)$ & 96 & 52641.84 \\
$4 \mathrm{f}) \phi(s y) p(s y) \beta(y)$ & 147 & 52667.15 \\
\hline
\end{tabular}

Notes: See Table 1 for a description of the submodels. The best-fit model (lowest AIC value) was one where $p$ varied based on an additive site and year effect (indicated in bold). Note that $\beta$ was set to vary on a yearly basis, based on the results from Table 3 . 
TABLE 2. Extended.

\begin{tabular}{|c|c|c|c|c|c|c|c|c|}
\hline \multicolumn{3}{|c|}{1994} & \multicolumn{3}{|c|}{1998} & \multicolumn{3}{|c|}{1999} \\
\hline$N$ & Surv (SE) & Length (SE) & $N$ & Surv (SE) & Length (SE) & $N$ & Surv (SE) & Length (SE) \\
\hline 1455 & $0.083(0.008)$ & $63.20(0.13)$ & 820 & $0.202(0.019)$ & $64.78(0.19)$ & 837 & $0.197(0.028)$ & $62.04(0.16)$ \\
\hline 727 & $0.273(0.019)$ & $75.17(0.22)$ & 467 & $0.385(0.027)$ & $79.52(0.29)$ & 389 & $0.353(0.042)$ & $74.01(0.29)$ \\
\hline 755 & $0.138(0.015)$ & $62.36(0.23)$ & 960 & $0.142(0.012)$ & $67.22(0.19)$ & 701 & $0.188(0.024)$ & $64.94(0.22)$ \\
\hline 1528 & $0.100(0.011)$ & $61.52(0.15)$ & & & & 763 & $0.189(0.018)$ & $60.98(0.18)$ \\
\hline 1442 & $0.110(0.009)$ & $61.84(0.16)$ & 270 & $0.248(0.042)$ & $61.29(0.31)$ & 423 & $0.202(0.055)$ & $60.56(0.22)$ \\
\hline 1512 & $0.101(0.010)$ & $66.66(0.14)$ & 700 & $0.219(0.019)$ & $67.60(0.19)$ & 660 & $0.212(0.023)$ & $64.94(0.20)$ \\
\hline 534 & $0.148(0.020)$ & $72.67(0.32)$ & 959 & $0.186(0.014)$ & $70.62(0.23)$ & 315 & $0.201(0.032)$ & $70.47(0.34)$ \\
\hline 405 & $0.106(0.019)$ & $62.72(0.33)$ & 545 & $0.189(0.030)$ & $67.08(0.32)$ & 603 & $0.151(0.021)$ & $64.62(0.25)$ \\
\hline 964 & $0.189(0.016)$ & $64.72(0.25)$ & 1029 & $0.317(0.022)$ & $66.93(0.20)$ & 719 & $0.237(0.026)$ & $62.80(0.23)$ \\
\hline 1575 & $0.115(0.009)$ & $68.88(0.16)$ & 769 & $0.225(0.017)$ & $69.87(0.22)$ & 554 & $0.147(0.021)$ & $66.19(0.26)$ \\
\hline 986 & $0.110(0.012)$ & $73.33(0.21)$ & & & & 674 & $0.137(0.017)$ & $65.36(0.23)$ \\
\hline 1571 & $0.090(0.009)$ & $59.01(0.13)$ & 998 & $0.120(0.012)$ & $62.92(0.17)$ & 1010 & $0.130(0.021)$ & $61.77(0.17)$ \\
\hline 1549 & $0.128(0.011)$ & $62.84(0.15)$ & 936 & $0.144(0.015)$ & $65.07(0.18)$ & 907 & $0.158(0.018)$ & $65.11(0.23)$ \\
\hline 728 & $0.175(0.017)$ & $61.97(0.20)$ & 443 & $0.140(0.019)$ & $62.57(0.23)$ & 838 & $0.217(0.022)$ & $60.32(0.18)$ \\
\hline 1551 & $0.067(0.007)$ & $64.14(0.14)$ & 1001 & $0.188(0.014)$ & $68.66(0.24)$ & 1009 & $0.132(0.016)$ & $64.27(0.17)$ \\
\hline
\end{tabular}

to conduct the survival modeling, we used the $\beta(y)$ and $p(s+y)$ submodels.

In relating survival patterns to group factors (Table 5, Fig. 4), we uncovered strong year and site effects by comparing models $5 \mathrm{e}$ (year effects) and $5 \mathrm{i}$ (site effects) to 5a (constant survival across site and years), with site effects explaining substantially more variability than year effects. However, a fully saturated survival model (unique survival for each site/year combination, model 5o) was by far the best performing group covariate model, even compared to a model where survival was related to the sum of a year and site term (model $5 \mathrm{~h}$ ).

We next added length-based covariates to the survival model (Table 5). Both mean length $(\bar{L})$ and delta length $(\delta)$ were significant factors when added to the model with constant survival across years and sites (comparing models $5 \mathrm{~b}$ and $5 \mathrm{c}$ to model $5 \mathrm{a}$ ), with the $\delta$ term conferring a substantially greater improvement in model fit than the $\bar{L}$ term. When we included both $\bar{L}$ and $\delta$ (model $5 \mathrm{~d}$ ), the improvement in AIC was almost equal to the sum of the AIC improvements for each covariate treated separately. Adding length covariates to the year-effects model (models $5 \mathrm{f}-\mathrm{h}$ ) produced improvements in AIC that were similar in magnitude to those observed in the previous models (models $5 b-d)$. When we added length covariates to a model already containing a site term, the decrease in AIC conferred by the $\delta$ term (comparing model $5 \mathrm{k}$ to $5 \mathrm{i}$ ) was roughly the same as in the previous cases. However, the effect of mean length was negligible (comparing models $5 \mathrm{j}$ and $5 \mathrm{i}$ ), implying that within sites,

TABLE 5. Results obtained from models based on varying the $\phi$ parameters (survival) with respect to site $(s)$, year $(y)$, mean length $(\bar{L})$, and individual deviation in length $(\delta)$ while holding fixed the structure of the $p$ (recapture probability) and $\beta$ parameters (combined downstream survival and recapture probability).

\begin{tabular}{lccrr}
\hline \hline \multicolumn{1}{c}{ Model } & No. parameters & AIC & $\Delta$ AIC (group) & $\Delta$ AIC (overall) \\
\hline 5a) $\phi$ & 25 & 53570.34 & 0.00 & 0.00 \\
5b) $\phi(\bar{L})$ & 26 & 53450.58 & -119.76 & -119.76 \\
5c) $\phi(\delta)$ & 26 & 53345.12 & -225.22 & -225.22 \\
5d) $\phi(\bar{L}+\delta)$ & 27 & 53233.02 & -337.32 & -337.32 \\
5e) $\phi(y)$ & 29 & 53349.03 & 0.00 & -221.31 \\
5f) $\phi(y+\bar{L})$ & 30 & 53234.24 & -114.79 & -336.09 \\
5g) $\phi(y+\delta)$ & 30 & 53123.40 & -225.63 & -446.94 \\
5h) $\phi(y+\bar{L}+\delta)$ & 31 & 53016.30 & -332.74 & -554.04 \\
5i) $\phi(s)$ & 39 & 52997.06 & 0.00 & -573.28 \\
5j) $\phi(s+\bar{L})$ & 40 & 52997.53 & 0.47 & -572.81 \\
5k) $\phi(s+\delta)$ & 40 & 52773.99 & -223.07 & -796.35 \\
51) $\phi(s+y)$ & 43 & 52791.58 & 0.00 & -778.76 \\
5m $\phi(s+y+\delta)$ & 44 & 52567.97 & -223.61 & -1002.37 \\
5n) $\phi(s y)$ & 95 & 52640.40 & 0.00 & -929.94 \\
5o) $\phi(s y+\delta)$ & 96 & 52416.77 & -223.63 & -1153.56 \\
\hline
\end{tabular}

Notes: See Table 1 for a description of the submodels. The AIC values were compared among all models (overall) and by group based on which group covariates were present. The best-fit model (lowest AIC value) was one where $\phi$ varied by a site-year interaction and $\delta$. Note that for all survival models, $p$ was set to the site + year effects models, and $\beta$ varied yearly based on the results from Tables 3 and 4. 

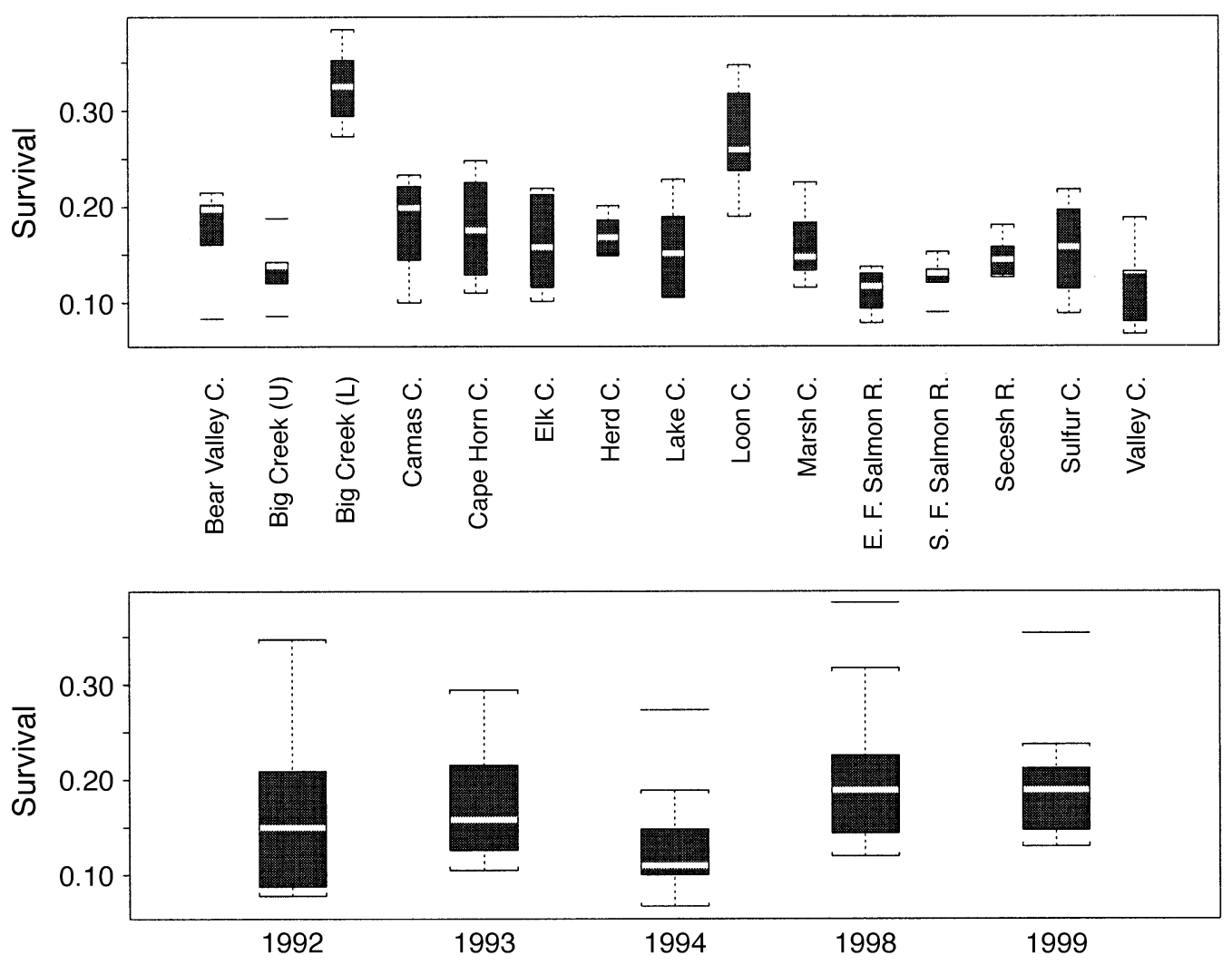

FIG. 4. Box plots (Cleveland 1993) of estimated population survival separated by site (top) and year (bottom). The plots present the median (open bar), upper and lower quartiles (range of the dark bars), upper and lower "adjacent values" (vertical lines with caps) and outliers (isolated horizontal lines). Survival estimates were based on the "saturated" model where a unique survival was estimated for each site-year combination.

year-to-year variability in survival was not related to year-to-year variability in mean length. Thus, we did not include mean length in more complex models that included site. Further analyses revealed that the relationship between survival and mean length is driven by the lower Big Creek population (Fig. 5). When we removed this population from the analysis, mean length conferred no improvement in model fit $(\Delta \mathrm{AIC}=$ $-1.04)$ when comparing model $5 \mathrm{~b}$ to $5 \mathrm{a}$, while the effect of $\delta$ was unchanged $(\Delta \mathrm{AIC}=224.07$ when comparing model $5 \mathrm{c}$ to $5 \mathrm{a}$ ). The lower Big Creek site is at least $400 \mathrm{~m}$ lower in elevation than the other sites, so removing it as an outlier has experimental design and statistical justification. Adding $\delta$ to models already containing both year and site effects (comparing model $5 \mathrm{~m}$ to 51 and $5 \mathrm{n}$ to $5 \mathrm{o}$ ) still conferred considerable improvement in model fit. In fact, adding $\delta$ to any group model conferred a nearly constant decrease in AIC, implying that within-population effects were independent of the group effects. Also, the fitted $\alpha$ (effect) parameter associated with the scaled $\delta$ was consistent across models (models $5 \mathrm{c}, 5 \mathrm{~g}, 5 \mathrm{k}, 5 \mathrm{~m}$, and 5o), ranging

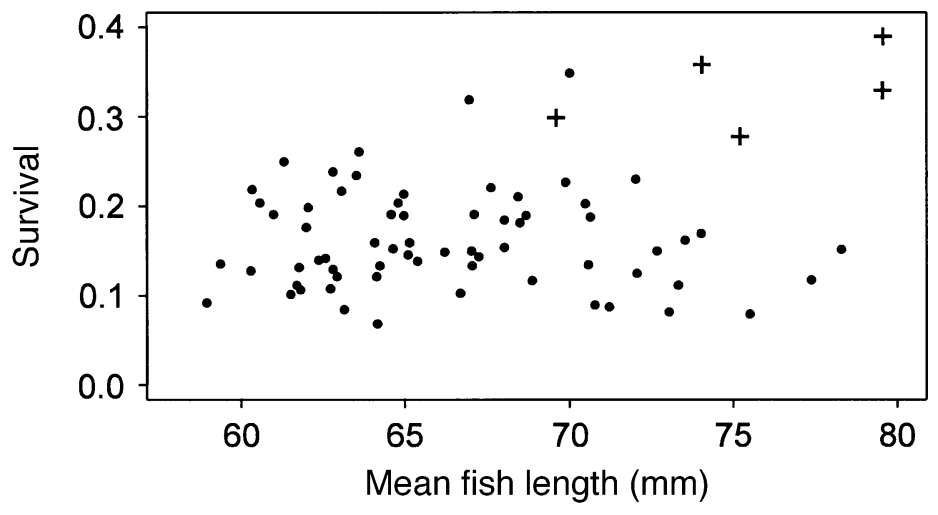

FIG. 5. Relationship between estimated population survival and mean fish length. Each point represents a single population in a single year. The "plus" (+) symbols represent the lower Big Creek release groups. 
FIG. 6. The solid line depicts percent survival $(\phi$, left axis) vs. delta length $(\delta, \mathrm{mm})$ based on model $5 \mathrm{c}$ (Table 5). The equation governing the relationship is $\phi(\delta)=[\exp (-1.69+$ $0.0329 \delta)] /[1+\exp (-1.69+0.0329 \delta)]$. The dashed line represents the percentage of delta lengths (by $1-\mathrm{mm}$ increments, right axis) in the entire population. The range of delta lengths in the plot represents $\sim 95 \%$ of the population.

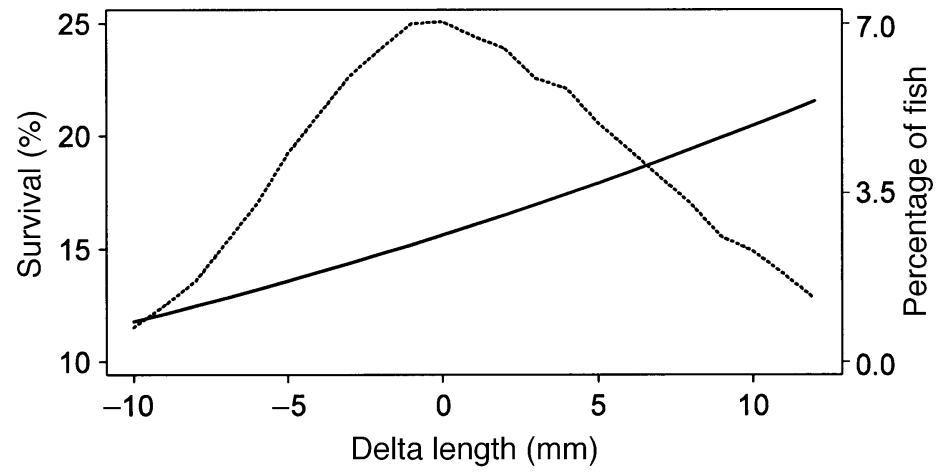

from 0.197 to 0.198 with $95 \%$ confidence intervals that overlapped when compared across all models. The effect of the $\delta$ was substantial: based on model $5 \mathrm{c}$, fish that were $10 \mathrm{~mm}$ above the mean had an almost twofold survival advantage compared to fish $10 \mathrm{~mm}$ below the mean (Fig. 6). The overall "best" model was one that contained unique site $\times$ year effects and a $\delta$ effect (model 5o). Parameter estimates for this model are provided in Appendix.

Analyzing condition index required reducing the data set to 26578 fish in 63 site-year combinations. The condition index, $K$, had little effect on survival (Table 6) whether expressed as population means (model $6 \mathrm{~b})$ or as individual deviations from population means (model 6c). The results changed little when individual length was included as a covariate. Since we found no effects in the simplest models, we did not analyze more elaborate models with condition index.

\section{DISCUSSION}

Since population viability reflects the integration of many survival processes, understanding how the components function and interact is a crucial element for restoring at-risk populations. This detailed study of survival of chinook salmon populations is an example of the first step in this process. One method of enhancing population viability is to improve the quality of individuals. Thus, it is essential to quantify how these improvements translate into increased survival and ultimately to increased population viability. Measuring effects over shorter life stages increases our ability to detect them, and we can convert improved survival over specific life stages to expected improvements in overall viability.

In some respects, the results we obtained were surprising. The most surprising result was that population survival was poorly predicted by mean length. We do not believe that lack of power contributed to this results: we tagged more than 54000 fish over five years in 15 populations. In contrast, we did observe that survival varied according to site and year effects. Other studies have related this variability to habitat condition (Paulsen and Fisher 2001), presence or absence of nonindigenous brook trout (Levin et al. 2002), and density dependence (Achord et al. 2003). However, these factors do not lead to changes in mean length that can reliably predict survival through the freshwater phase. These results do not necessarily indicate that absolute size is not an important factor in these populations, as the lack of an effect during one life stage does not preclude realization of effects in a later life stage. However, the results do indicate that we cannot simply assume that mean length is an appropriate surrogate for population survival in monitoring programs, or that increasing size will result in increased population viability.

When we analyzed variability in survival within populations, the surprising result was that condition index $(K)$ was not related to survival within populations, even after length was taken into account. One proposed mechanism for size-selective mortality in fish populations is differential susceptibility to starvation (Sogard 1997). Our results do not support this hypothesis for these fish during the freshwater phase since the

TABLE 6. Survival $(\phi)$ models involving condition index $(K)$ and length $(l)$.

\begin{tabular}{lcccc}
\hline \hline \multicolumn{1}{c}{ Model } & No. parameters & AIC & $\Delta$ AIC (group) & $\Delta$ AIC (overall) \\
\hline 6a) $\phi$ & 25 & 26864.86 & 0.00 & 0.00 \\
6b) $\phi(\bar{K})$ & 26 & 26863.88 & -0.97 & -0.97 \\
6c) $\phi\left(\delta_{K}\right)$ & 26 & 26866.50 & 1.64 & 1.64 \\
6d) $\phi(l)$ & 26 & 26685.18 & 0.00 & -179.67 \\
6e) $\phi(l+\bar{K})$ & 27 & 26685.39 & 0.21 & -179.46 \\
6f) $\phi\left(l+\delta_{K}\right)$ & 27 & 26687.12 & 1.94 & -177.73 \\
\hline
\end{tabular}

Note: For all survival models, $p$ (recapture probability) was set to the site + year effects model, and $\beta$ (combined downstream survival and recapture probability) varied yearly, based on the results from Tables 3 and 4. 


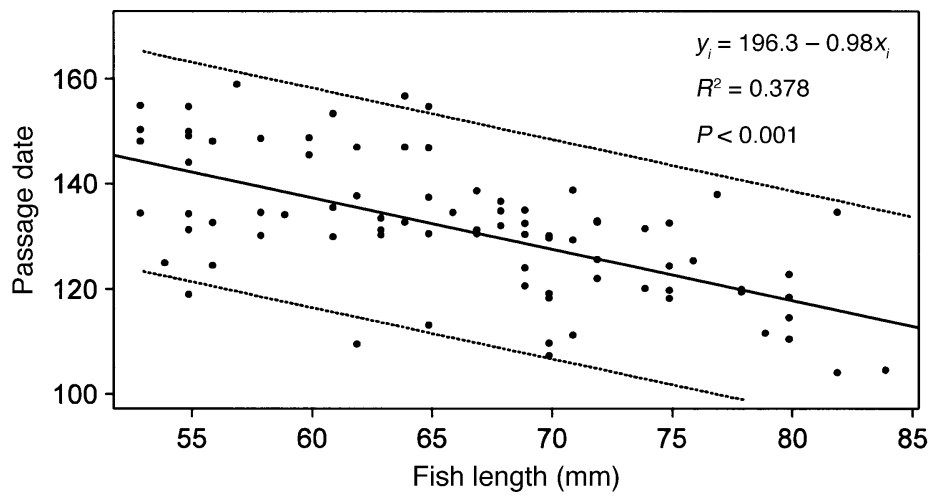

FIG. 7. Date (day of the year with day 140 $=20$ May) that individuals passed Lower Granite Dam vs. fish length $(\mathrm{mm})$ for Loon Creek fish released in 1994. The solid line is based on a simple linear regression, and the dotted lines are the $95 \%$ confidence intervals of the data. condition index had no bearing on its survival. In contrast, the relative length of individuals $(\delta)$ was a consistently important factor in any model that included it, and the magnitude of this effect was large.

The fact that we observed relative length effects within populations but not absolute length effects among populations appeared paradoxical at first. Our results, though, are consistent with mechanisms where selective forces operate on relative, not absolute, sizes of individuals. Below we propose several hypotheses that are consistent with our results and with information on the population biology of salmonines.

The first hypothesis is that juvenile salmon compete for territories with larger individuals consistently occupying better sites. Stream-type chinook are territorial during the freshwater rearing phase (Taylor and Larkin 1986, Taylor 1988, 1990, Healy 1991), demonstrating antagonistic behavior toward conspecifics. If larger fish occupy higher quality sites with better feeding opportunities and less risk of predation, presumably they will have higher survival rates. This type of size-based hierarchical behavior in terms of occupying preferable habitats has been demonstrated for stream-dwelling juveniles of brown trout (Salmo trutta) (Elliot 1990, 1994). Reinhardt and Healey (1997) proposed a similar mechanism to explain size-related, differential habitat usage by coho salmon (Oncorhynchus kisutch). They suggested that in the presence of predators, larger fish were more risk averse than smaller fish, which occupied energetically more favorable but riskier habitats.

The second hypothesis is based on the observation that longer chinook undergo seaward migration earlier (Zabel 2002), and thus size is an indicator of developmental level. This is supported by the fact that longer fish arrive at Lower Granite Dam earlier (Fig. 7). Each population has distinct migrational timing (Achord et al. 1996), so the arrival timing versus length relationship exists on a per-population basis. Thus our second hypothesis is that larger fish within populations have relatively higher juvenile survival, at least partially, because they spend less time exposed to hazards such as predators.

\section{Linking together life stages}

As alluded to in the introduction, the full survival effects related to the condition of individuals might not be expressed during one life stage. For instance, if trait $X$ was measured during life stage 1 , it might have an effect on survival during life stage 1 but also on survival during life stage 2 . We can express the effect of $X$ through both life stages as

$$
S_{1+2}(x)=S_{1}(x) \times S_{2}(x) .
$$

Trait $X$ might affect survival during life stage 2 because it is correlated with a trait $Y$ that affects stage 2. Correlations between quantitative traits are never perfect, so we need to consider the conditional probability density function for $Y$ in life stage 2 given a value of $X$ in stage 1 , or $P(y \mid x)$. In this case, the effect of trait $X$ on the successive life stage 2 is

$$
S_{2}(x)=\int_{y-\min }^{y-\max } P(y \mid x) \times S_{2}(y) d y .
$$

This integrates over all possible values of trait $Y$ weighted by their probability of occurrence given $x$, and multiplies this by the survival associated with specific values $y$. This only considers the effects of trait $X$ on one other trait, so it does not fully describe the interdependency between life stages; however describing only a part of this interdependency can illuminate survival and selection processes.

To demonstrate this, we considered how length $(x)$ measured during the juvenile rearing stage is correlated with arrival timing at Lower Granite Dam (y) the following year and then the relationship between arrival timing at Lower Granite Dam and survival to the adult return phase $\left(S_{2}(y)\right)$ as provided by Zabel and Williams (2002) for the seaward migration year 1995. Since migrational timing was variable among populations, we considered just one population, Loon Creek, which had an intermediate passage timing and mean fish length. Passage timing at Lower Granite Dam in 1995 was negatively related to juvenile length measured in 1994 (Fig. 7). Assuming a normal error structure, we deter- 
mined the probability density function of passage timing at Lower Granite Dam given juvenile length $(P(y \mid x))$. For the survivorship function during the first stage related to juvenile length $\left(S_{1}(x)\right)$, we used the functional form of model 5o (Table 5) shifted by the population mean for Loon Creek in 1994. Thus, we have all components of Eqs. 5 and 6.

By applying the distribution of lengths observed in the Loon Creek population to Eqs. 5 and 6, we predicted differential survivorship through both life stages with respect to juvenile length, as measured by the directional selection coefficients (the difference in the mean value of a trait before and after selection, divided by its preselection standard deviation [Endler 1986]). The selection coefficient with respect to juvenile length during the first stage was 0.27 . When we added the effects of juvenile length on downstream arrival timing, the estimated selection coefficient through both stages increased to 0.43 , almost a $60 \%$ increase. Thus longer juveniles not only had a selective advantage during the freshwater phase, but their earlier migrational timing potentially conferred a strong selective advantage during the ocean phase too. For these fish, growth during the first summer had a strong impact on survival processes through their entire lifetime. We do not imply that this type of effect will be observed in all cases. For example, selection for migration timing was not as strong in 1996 as it was in 1995 (Zabel and Williams 2002). However, we do want to emphasize that measures of population performance that focus on a single life stage may ignore the full effects of variability in individuals.

In summary, the consistent relationships between relative size within a population and probability of survival provide clues to underlying mortality mechanisms. Given the importance of the juvenile phase to the overall viability of these salmon populations, conducting experiments to further elucidate these mechanisms is a potentially fruitful avenue for research. Also, most demographic-modeling efforts focused on at-risk populations attempt to predict the increase in population viability in response to increases in survival during a particular life stage. Our results suggest that improvements in survival in one life stage may lead to improved survival in subsequent life stages. Since demographic models form the cornerstone of many species recovery efforts (Morris et al. 1999), further research on the effects of the interdependency of life stages on population viability is clearly warranted.

\section{ACKNOWLEDGMENTS}

Peter Kareiva, John Williams, Beth Sanderson, Doug Dey, Charlie Paulsen, and Steven Smith provided valuable input to this paper. Blake Feist created Fig. 1. We thank Neil N. Paasch, Kenneth W. McIntyre, Eric E. Hockersmith, Gordon A. Axel, Douglas M. Marsh, M. Brad Eppard, Benjamin P. Sandford, Jeffery L. Moser, Ron A. Marr, Charles J. Ebel, Jonathan H. Kohr, Richard Burland, Gary Foust, Daniel J. Kamikawa, Gene M. Matthews, and several other field assistants for their excellent help in collecting and PIT tagging fish for this study. The field work was funded by the Bonneville Power Administration.

\section{Literature Cited}

Achord, S., E. B. Eppard, E. Hockersmith, B. Sandford, G. Axel, and G. Mathews. 2001. Monitoring the migration of wild Snake River spring/summer chinook salmon smolts, 2000. Report to Bonneville Power Administration, Portland, Oregon, USA.

Achord, S., P. S. Levin, and R. W. Zabel. 2003. Densitydependent mortality in Pacific salmon: the ghost of impacts past? Ecology Letters 6:335-342.

Achord, S., G. M. Mathews, O. W. Johnson, and D. M. Marsh. 1996. Use of passive integrated transponder (PIT) tags to monitor migration timing of Snake River chinook salmon smolts. North American Journal of Fisheries Management 16:302-313.

Akaike, H. 1973. Information theory and an extension of the maximum likelihood principle. Pages 267-281 in B. N. Petrov and F. Csaki, editors. Proceedings of the Second International Symposium on Information Theory. Akademiai Kiado, Budapest, Hungary.

Anderson, R. O., and S. Gutreuter. 1983. Length, weight and associated structural indices. Pages $283-300$ in L. A. Nielsen and D. L. Johnson, editors. Fisheries techniques. American Fisheries Society, Bethesda, Maryland, USA.

Baras, E., C. Malbrouck, M. Houbart, P. Kestemont, and C. Mélard. 2000. The effect of PIT tags on growth and physiology of age- 0 cultured Eurasian perch Perca fluviatilis of variable size. Aquaculture 185:159-173.

Begon, M., M. Mortimer, and D. J. Thompson. 1996. Population ecology, a unified study of animals and plants. Third edition. Blackwell Science, Oxford, UK.

Burnham, K. P., and D. R. Anderson. 1998. Model selection and inference-a practical information-theoretic approach. Springer-Verlag, New York, New York, USA.

Burnham, K. P., D. R. Anderson, G. C. White, C. Brownie, and K. H. Pollock. 1987. Design and analysis methods for fish survival experiments based on release-recapture. Monograph No. 5. American Fisheries Society, Bethesda, Maryland, USA.

Campbell, S. P., J. A. Clark, L. H. Crampton, A. D. Guerry, L. T. Hatch, P. R. Hosseini, J. J. Lawler, and R. J. O'Connor. 2002. An assessment of monitoring efforts in endangered species recovery plans. Ecological Applications 12:674681.

Cleveland, W. S. 1993. Visualizing data. Hobart Press, Summit, New Jersey, USA.

Crowder, L. B., D. T. Crouse, S. S. Heppell, and T. H. Martin. 1994. Predicting the impact of turtle excluder devices on loggerhead sea turtle populations. Ecological Applications 4:437-445.

Doak, D., P. Kareiva, and B. Klepetka. 1994. Modeling population viability for the desert tortoise in the Western Mojave Desert. Ecological Applications 4:446-460.

Elliot, J. M. 1990. Mechanisms responsible for population regulation in young migratory trout, Salmo trutta. Journal of Animal Ecology 59:803-818.

Elliot, J. M. 1994. Quantitative ecology and the brown trout. Oxford University Press, Oxford, UK.

Endler, J. A. 1986. Natural selection in the wild. Princeton University Press, Princeton, New Jersey, USA.

Folmar, C. F., and W. W. Dickhoff. 1980. The parr-smolt transformation (smoltification) and seawater adaptation in salmonids. Aquaculture 21:1-37.

Gilbert, C. H. 1912. Age at maturity of the Pacific coast salmon of the genus Oncorhynchus. Bulletin of the Bureau of Fisheries (U.S.) 32:1-22.

Goater, C. P. 1994. Growth and survival of postmetamorphic toads: interactions among larval history, density, and parasitism. Ecology 75:2264-2274. 
Healy, M. C. 1991. Life history of chinook salmon. Pages 311-393 in C. Groot and L. Margolis, editors. Pacific salmon life histories. University of British Columbia Press, Vancouver, British Columbia, Canada.

Hoar, W. S. 1976. Smolt transformation: evolution, behavior, and physiology. Journal of the Fisheries Research Board of Canada 33:1234-1252.

Kareiva, P., M. Marvier, and M. McClure. 2000. Recovery and management options for spring/summer chinook salmon in the Columbia River Basin. Science 290:977-979.

Lande, R. 1988. Demographic models of the Northern spotted Owl (Strix occidentalis caurina). Oecologia 75:601-607.

Lawler, J. L., S. P. Campbell, A. D. Guerry, M. B. Kolozsvary, R. J. O'Connor, and L. C. N. Seward. 2002. The scope and treatment of threats in endangered species recovery plans. Ecological Applications 13:663-667.

Lebreton, J.-D., K. P. Burnham, J. Clobert, and D. R. Anderson. 1992. Modeling survival and testing biological hypotheses using marked animals: a unified approach with case studies. Ecological Monographs 62:67-118.

Lebreton, J.-D., R. Pradel, and J. Clobert. 1993. The statistical analysis of survival in animal populations. Trends in Ecology and Evolution 8:91-95.

Levin, P. S., S. Achord, B. E. Feist, and R. W. Zabel. 2002. Non-indigenous brook trout and the demise of Pacific salmon: a forgotten threat? Proceedings of the Royal Society of London (B) 269:1663-1670.

Łomnicki, A. 1988. Population ecology of individuals. Princeton University Press, Princeton New Jersey, USA.

MacKenzie, D. I., and W. L. Kendall. 2002. How should detection probability be incorporated into estimates of relative abundance. Ecology 83:2387-2393.

Mathews, G. M., and R. S. Waples. 1991. Status review for Snake River spring and summer chinook salmon. U.S. Department of Commerce, NOAA Technical memo. Northwest Fisheries Science Center, Seattle, Washington, USA.

Mood, A. M., F. A. Graybill, and D. C. Boes. 1974. Introduction to the theory of statistics. Third edition. McGrawHill Book Company, New York, New York, USA.

Morris, W., D. Doak, M. Groom, P. Kareiva, J. Fieberg, L. Gerber, P. Murphy, and D. Thomson. 1999. A practical handbook for population viability analysis. The Nature Conservancy, Washington, D.C., USA.

Paulsen, C. M., and T. R. Fisher. 2001. Statistical relationship between parr-to-smolt survival of Snake River spring-summer chinook salmon and indices of land use. Transactions of the American Fisheries Society 130:347-358.

Peterson, N. P., E. F. Prentice, and T. P. Quinn. 1994. Comparison of sequential coded wire and passive integrated transponder tags for assessing overwinter growth and survival of juvenile coho salmon. North American Journal of Fisheries Management 14:870-873.

Phillips, N. E. 2002. Effects of nutrition-mediated larval condition on juvenile performance in a marine mussel. Ecology 84:2562-2574.

Prentice, E. F., T. A. Flagg, and C. S. McCutcheon. 1990. Feasibility of using implantable passive integrated transponder (PIT) tags in salmonids. American Fisheries Society Symposium 7:317-322.
Reinhardt, U. G., and M. C. Healey. 1997. Size-dependent foraging behaviour and use of cover in coho salmon under predation risk. Canadian Journal of Zoology 75:16421651.

Ricker, W. E. 1975. Computation and interpretation of biological statistics of fish populations. Bulletin 191. Fisheries Research Board of Canada, Ottawa, Ontario, Canada.

Searcy, S. P., and S. Sponaugle. 2001. Selective mortality during the larval-juvenile transition in two coral reef fishes. Ecology 82:2452-2470.

Skalski, J. R., S. G. Smith, R. N. Iwamoto, J. G. Williams, and A. Hoffmann. 1998. Use of passive integrated transponder tags to estimate survival of migrant juvenile salmonids in the Snake and Columbia Rivers. Canadian Journal of Fisheries and Aquatic Sciences 55:1484-1493.

Sogard, S. M. 1997. Size-selective mortality in the juvenile stage of teleost fishes: a review. Bulletin of Marine Science 60: $1129-1157$.

Stephens, D. W., and J. R. Krebs. 1986. Foraging theory. Princeton University Press, Princeton, New Jersey, USA.

Sutherland, W. J. 1996. From individual behaviour to population ecology. Oxford University Press, New York, New York, USA.

Taylor, E. B. 1988. Adaptive variation in rheotactic and agonistic behavior in newly emerged fry of chinook salmon, Oncorhynchus tshawytscha, from ocean- and stream-type populations. Canadian Journal of Fisheries and Aquatic Sciences 45:237-243.

Taylor, E. B. 1990. Phenotypic correlates of life-history variation in juvenile chinook salmon, Oncorhynchus tshawytscha. Journal of Animal Ecology 59:455-468.

Taylor, E. B., and P. A. Larkin. 1986. Current response and agonistic behavior in newly emerged fry of chinook salmon, Oncorhynchus tshawytscha, from ocean- and streamtype populations. Canadian Journal of Fisheries and Aquatic Sciences 43:565-573.

Werner, E. E. 1988. Size, scaling, and the evolution of complex life histories. Pages 60-84 in B. Ebenman and L. Persson, editors. Size-structured populations, ecology and evolution. Springer-Verlag, Berlin, Germany.

Werner, E. E., and B. R. Anholt. 1993. Ecological consequences of the trade-off between growth and mortality rates mediated by foraging activity. American Naturalist 142: 242-272.

Werner, E. E., and J. F. Gilliam. 1984. The ontogenetic niche shift and species interactions in size-structured populations. Annual Review of Ecology and Systematics 15:393-426.

White, G. C., and K. P. Burnham. 1999. Program MARK: survival estimation from populations of marked animals. Bird Study Supplement 46:120-138.

Wilbur, H. M. 1980. Complex life cycles. Annual Review of Ecology and Systematics 11:67-93.

Wisdom, M. J., L. S. Mills, and D. F. Doak. 2000. Life stage simulation analysis: estimating vital-rate effects on population growth for conservation. Ecology 81:628-641.

Zabel, R. W. 2002. Using "travel-time" data to characterize the behavior of migrating animals. American Naturalist 159:372-387.

Zabel, R. W., and J. G. Williams. 2002. Selective mortality in chinook salmon: What is the role of human disturbance? Ecological Applications 12:173-183.

\section{APPENDIX}

A table showing the parameter estimates for the best-fit survival model (model 5o) is presented in ESA's Electronic Data Archive: Ecological Archives E085-021-A1. 